\title{
Influência do uso e ocupação na qualidade da água no Rio Pirarara, afluente do Rio Machado, Rondônia/Brasil
}

O presente estudo trata de uma discussão sobre a influência do uso e ocupação das terras na qualidade da água da bacia do Rio Pirarara, no município de CacoalRondônia. A metodologia de trabalho consistiu na realização de coleta de dados, informações e imagens, e para constatar esta influência, utilizou-se um Sistema de Informação Geográfica e técnicas de sensoriamento remoto para a integração das informações acerca do uso das terras. Na área da bacia o processo de ocupação irregular e o lançamento de esgoto interferem negativamente na qualidade da água e consequentemente as atividades antrópicas transformam as paisagens. Desta forma, foi confirmado que, as áreas ocupadas por vegetação favorecem a qualidade do ambiente. Sendo que, os efeitos destas atividades se fez evidente também nas áreas rurais em função do processo de ocupação para as atividades agropastoril. Constatou-se que o uso agrossilvipastoril é predominante na bacia, sendo capaz de inferir que este exerce um papel fundamental na economia da região. De maneira geral, as áreas urbanas, agricultadas e com pastagens, interferem na qualidade ambiental.

Palavras-chave: Qualidade da Água; Uso do Solo; Bacia Hidrográfica.

\section{Influence of use and occupation in water quality in the Pirarara River, affluent of Machado River, Rondônia/Brazil}

\begin{abstract}
The present study deals with a discussion about the influence of land use and occupation on the water quality of the Pirarara hidrographic basin, in the city of Cacoal, state of Rondônia. The work methodology consisted in collection of data, information and images, and to verify this influence, a Geographic Information System and remote sensing techniques were used to integrate information about land use. In the basin area, the process of irregular occupation and the discharge of sewage interfere negatively in the quality of life and consequently the anthropic activities transform the landscapes. In this way, it was confirmed that the areas occupied by vegetation favor the quality of the environment. The effects of these activities were also evident in rural areas due to the occupation process for agropastoral activities. It was verified that the use of agrisilvipasture is predominant in the basin, being able to infer that it plays a fundamental role in the economy of the region. In general, urban areas, grazed and pasture, interfere in the environmental quality.
\end{abstract}

Keywords: Water Quality; Land Use; Hydrographic Basin.

Topic: Hidrogeografia

Reviewed anonymously in the process of blind peer.
Received: $10 / 08 / 2018$

Approved: 24/09/2018
Luzinete Scaunichi Barbosa (iD)

Universidade do Estado de Mato Grosso, Brasil

http://lattes.cnpq.br/8151654765247591

http://orcid.org/0000-0002-5495-1130

scaunichibarbosa@hotmail.com

Eliomar Pereira da Silva Filho (it)

Universidade Federal de Rondônia, Brasil

http://lattes.cnpq.br/2651173141421798

http://orcid.org/0000-0002-6271-8435

eliomarpsfilho@gmail.com

\section{Referencing this:}

BARBOSA, L. S.; SILVA FILHO, E. P.. Influência do uso e ocupação na qualidade da água no Rio Pirarara, afluente do Rio Machado, Rondônia/Brasil. Revista Ibero Americana de Ciências Ambientais, v.9, n.7, p.320-332, 2018. DOI: http://doi.org/10.6008/CBPC2179$\underline{6858.2018 .007 .0030}$

DOI: 10.6008/CBPC2179-6858.2018.007.0030 


\section{INTRODUÇÃO}

O processo de ocupação da terra em áreas urbanas ou rurais tem ocasionado algumas preocupações, principalmente em estudos de bacias hidrográficas que abrangem áreas rurais ou urbanas. Nas cidades os processos de ocupação apresentam-se cada vez mais intenso, de forma desordenada e com usos inadequados, sem planejamento eficiente. Fatores que se apresentam de formas sucessivas devido ao crescimento da população urbana que tem ocorrido de forma explosiva, marcado pela falta de políticas de ordenação e proteção das áreas drenadas pelo rio.

Sabendo que os recursos existentes são de interesse coletivo para garantir a qualidade de vida. Desde o início da industrialização, observou-se a uma crescente intervenção dos processos produtivos sobre o substrato natural. As variadas transformações climáticas em diferentes escalas, decorrentes da urbanização acelerada, a destruição da cobertura vegetal, os gases e partículas sólidas lançados pelas indústrias e o envenenamento das águas em geral são as manifestações mais eloquentes dessa contradição (MORAES, 1984).

Guerra et al. (1996) enfatizam que o ambiente é o espaço onde as formas de vida se desenvolvem, seja, animal ou vegetal, a qual o homem também está inserido. Afirmando que, ele "é o resultado do modelo de comportamento de uma sociedade de consumo" e salientam que o aumento na produção da sociedade é, sem dúvida, a maior responsável pelos problemas ambientais.

A ação do homem sobre a natureza, por muitas vezes se apresenta de forma exploratória, com uma busca desordenada por seus recursos, contribuindo para um desequilíbrio no meio ambiente. Conforme Mendonça (2004), o meio ambiente é visto em uma nova abordagem Geográfica, como um recurso a ser utilizado e como tal deve ser analisado e protegido, de acordo com suas diferentes condições.

De acordo com Bueno et al. (2005), o crescimento demográfico e o desenvolvimento socioeconômico estão sempre acompanhados pela necessidade de água, cuja qualidade e quantidade são de grande importância para a saúde e desenvolvimento de qualquer grupo. Na área urbana a alteração motivada pela ocupação do espaço promove importantes transformações, onde se destaca a impermeabilização do terreno, através das edificações e da pavimentação das vias de circulação (CAVALHEIRO, 1995; PORTO et al., 2001; BOTELHO et al., 2002; COSTA, 2002; VITTE, 2004).

Entretanto, Pereira (1997) enfatiza que, em uma bacia hidrográfica o clima, a geologia, a topografia, a vegetação, bem como o tipo de solo e seu manejo podem influenciar na qualidade hídrica. No entanto, a degradação da água pode ser proveniente do seu próprio uso como também dos diversos usos do solo, notadamente os usos agrícolas, industrial e urbano. Assim, influências antrópicas promovidas pelo uso e ocupação da terra sobre a qualidade da água estão fortemente associadas ao crescimento da urbanização, da expansão das atividades agropecuárias e industriais. Deste modo, há a necessidade de enquadramento dos recursos hídricos aos diferentes níveis de qualidade, já que se designam a usos múltiplos (ARAúJO, 2003). $\mathrm{Na}$ área urbana a modificação gerada pela ocupação do espaço é responsável por importantes alterações, 
onde se destaca a impermeabilização do terreno, através das edificações e da pavimentação das vias de circulação.

\section{Localização da área de estudo}

A bacia hidrográfica do Rio Pirarara com uma área de $123,80 \mathrm{~km}^{2}$, abrangendo o ambiente rural e urbano, localiza-se no município de Cacoal-Rondônia, afluente da margem direita do Rio Machado (figura 1).

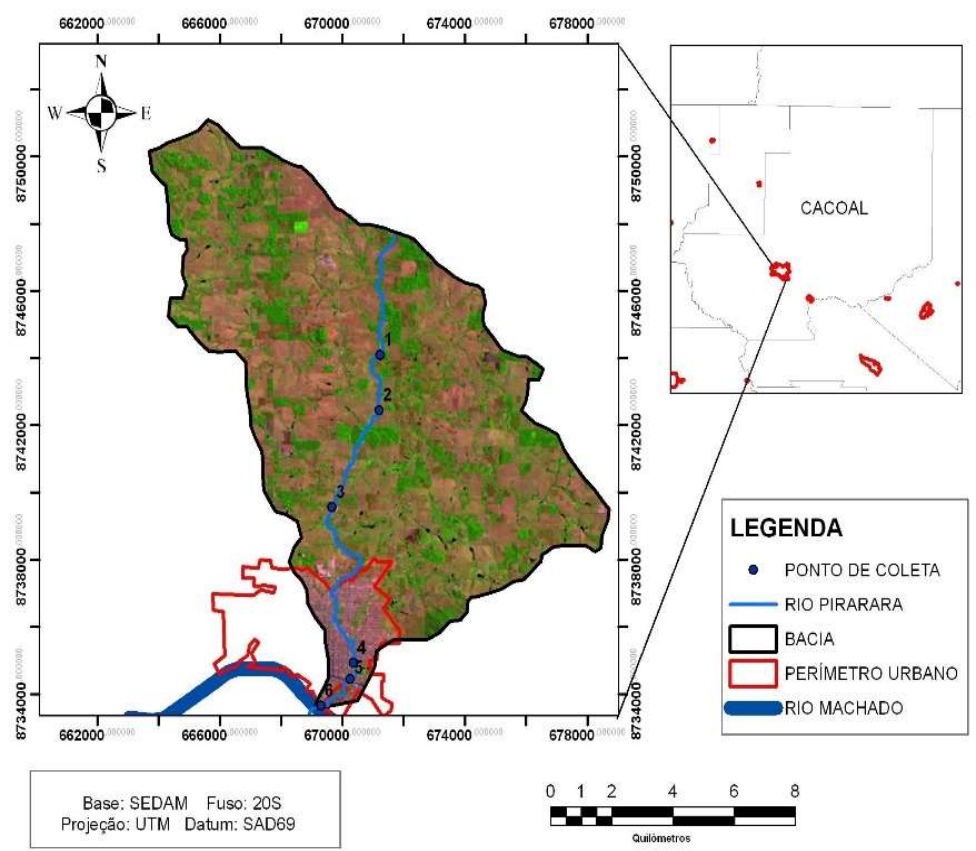

Figura 1: Mapa de localização da área de estudo. Fonte: Base SEDAM.

\section{Caracterização da área de estudo}

Em 1972, o Instituto Nacional de Colonização e Reforma Agrária (INCRA) implantou o Projeto Integrado de Colonização Gy Paraná, onde foram assentadas 4.756 famílias. Fato que favoreceu a ocupação no entroncamento do rio com a BR-364, promovendo à formação da vila Cacoal. A região tornou-se polo de atração, principalmente de agricultores da região sul e sudeste do país, que motivados pelas terras que eram propícias ao cultivo de lavouras de café. Essa busca fez com que o fluxo migratório se intensificasse a partir de 1972 e em 1975, a população já ultrapassava os 10 mil habitantes, tornando-se um desafio constante para o governo que não conseguia suprir as deficiências de muitos setores (KEMPER, 2006).

Atualmente sua economia tem como base as indústrias de grande porte, a agropecuária e o comércio. Sua prosperidade e expansão econômica se destacam frente aos demais municípios da região, com um PIB (Produto Interno Bruto) de R\$ 832, 767 milhões. Na área da bacia as terras apresentam um alto grau de fertilidade, devido a sua composição variada, sendo utilizadas em diversos tipos de cultura conforme Zoneamento Socioeconômico (RONDÔNIA, 2010). As unidades pedológicas pertencem a grupos, onde predominam os latossolos. Sendo composto também por solos Litólicos eutróficos e por Podzólicos vermelho-escuros eutróficos e com menor representação os Cambissolos distróficos. 
$\mathrm{Na}$ região, a vegetação dominante é classificada pela transição entre floresta e savana. Sendo composta pela existência de floresta densa, do tipo amazônico, com ampla variedade de espécies de plantas ornamentais, medicinais, alimentícias e de madeira-de-lei, e uma pequena parte, de vegetação tipo cerrado. No entanto, parte da vegetação natural foi destruída, principalmente no início do processo da ocupação, para a desenvolvimento de lavouras e pastagens. Porém, essa formação vegetal foi praticamente eliminada, devido à procura pelo seu valor comercial e para as atividades agropastoril levando ao intenso desmatamento fator que contribui para o elevado índice de desmatamento nas últimas décadas. Segundo dados do INPE, a área desmatada de Cacoal passou de 0,3\%, em 1970, para 82\%, em 1995, devido à especulação latifundiária, evidenciando altíssima pressão antrópica sobre os recursos naturais, trazendo como consequência os problemas ambientais, como o assoreamento dos rios e igarapés e contaminação pelos lançamentos de resíduos comprometendo a qualidade da água (KEMPER, 2006).

O clima tropical quente e úmido, com duas estações: verão chuvoso e inverno seco, predomina na região. A temperatura é elevada o ano todo, com média de $25^{\circ} \mathrm{C}$. Segundo a classificação de Köppen, o clima é do tipo Aw, o qual estando sob a influência do clima Aw com média anual da precipitação pluviométrica variando entre 1.600 a $2.300 \mathrm{~mm} / \mathrm{ano}$ (SILVA, 2006).

\section{MATERIAIS E MÉTODOS}

O trabalho foi realizado na bacia do Rio Pirarara no município de Cacoal, no Estado de Rondônia. A análise da influência do uso e ocupação da terra foi obtida através das informações coletadas em campo e pelas imagens LANDSAT e SPOT da área da Bacia Hidrográfica do Rio Pirarara. As informações forneceram elementos para a caracterização da área e para elaboração do mapeamento de uso e ocupação da terra que, foram identificadas e classificadas nos trabalhos de campo através de observações próximas aos pontos de coleta de água e analisadas através das imagens de satélites, criando o mapa de uso da terra. Desta forma, foi gerado um banco de dados, por meio de técnicas manuais, sobre dados cartográficos e sobre as imagens de satélites, visando compartimentalizar, estas novas informações que contribuíram para a geração de mapas temáticos. A espacialização das informações foi realizada no software SPRING através de shapes files. Para a demarcação dos usos e ocupação das terras, foram utilizadas as classes observadas em campo e mosaicos de imagens (tabela 1 ).

Tabela 1: Classes de usos da Terra.

\begin{tabular}{|l|l|}
\hline CLASSES & Usos da Terra \\
\hline $\begin{array}{l}\text { Fragmento } \\
\text { florestal }\end{array}$ & $\begin{array}{l}\text { Coberturas florestais arbóreo/arbustivo, com dossel denso e aberto, e áreas de reflorestamento em } \\
\text { processo avançado de sucessão, como as florestas nativas, plantadas e capoeirões; }\end{array}$ \\
\hline $\begin{array}{l}\text { Agrossilvipastoril } \\
-\end{array}$ & $\begin{array}{l}\text { Uso agropastoril, cultivo da agricultura temporária ou permanente; pecuária, áreas de reflorestamento } \\
\text { ainda em fase inicial de sucessão e os campos com árvores dispersas áreas com pastagem natural ou } \\
\text { plantada; }\end{array}$ \\
\hline Área urbana & Edificações e aglomerados, urbanizadas, destinadas à indústria, as vias asfaltadas, bem como o solo exposto. \\
\hline Água & Cursos d'água onde se incluem rios e córregos. \\
\hline Mineração & Exploração de granito, areia e brita. \\
\hline
\end{tabular}

Em seguida, foi gerado o mapa com as imagens LANDSAT do Instituto de pesquisas Espaciais - INPE (2017), analisadas ao nível de pixel, por meio do software SPRING, e como dados auxiliares foram utilizados 
as vias interurbanas e hidrográficas da base da Secretaria Estadual de Desenvolvimento Ambiental SEDAM. A imagem SPOT foi utilizada para a correção das áreas geradas pelo LANDSAT, comparando os resultados produzidos e gerando as áreas verdadeiras. Desta forma, a verificação in loco, foi de grande importância para determinar a conformidade das classes geradas pelas imagens e suas correções.

Para a caracterização da qualidade da água, foram determinados 5 pontos de coleta em área urbana e rural, para análise de parâmetros físico-químicos e biológicos, considerados indicadores da qualidade da água, cujos resultados demonstram consonância ou não, de acordo com os parâmetros estabelecidos conforme a legislação vigente na CONAMA, 357/2005. As amostras foram coletadas em dois períodos distintos, ou seja, na estação seca e chuvosa, durante o ano de 2017, perfazendo um total de 4 coletas.

Tabela 2: Parâmetros para a caracterização da qualidade da água.

\begin{tabular}{|c|c|}
\hline $\begin{array}{l}\text { Parâmetros } \\
\text { físicos }\end{array}$ & Turbidez (NTU), Cor (uH), e Temperatura $\left({ }^{\circ} \mathrm{C}\right)$; \\
\hline $\begin{array}{l}\text { Parâmetros } \\
\text { químicos }\end{array}$ & $\begin{array}{l}\mathrm{pH} \text {, Nitrito }(\mathrm{mg} / \mathrm{l}) \text {, Nitrato }(\mathrm{mg} / \mathrm{l}) \text {, Fósforo Total }(\mathrm{mg} / \mathrm{l}) \text {,alcalinidade, Ferro }(\mathrm{mg} / \mathrm{l}) \text {,Cromo }(\mathrm{mg} / \mathrm{l}) \text {, Cobre }(\mathrm{mg} / \mathrm{l}) \\
\text { Demanda Química de Oxigênio - DQO }(\mathrm{mg} / \mathrm{l}) \text {, Oxigênio Dissolvido - OD }(\mathrm{mg} / \mathrm{l}) \text {. }\end{array}$ \\
\hline $\begin{array}{l}\text { Parâmetros } \\
\text { biológicos }\end{array}$ & $\begin{array}{l}\text { Coliformes Totais (NMP/100ml) e Coliformes } \\
\text { Fecais (NMP/100ml). }\end{array}$ \\
\hline
\end{tabular}

Para as análises em laboratório, seguiu a metodologia prevista na literatura existente, através do Método para as Análises de Águas Potáveis e Residuárias - Standard Methods for Examination of Water and Wastewater (APHA, 2005). O trabalho abrangeu a preparação das amostras coletadas e análise através da leitura dos parâmetros no aparelho Multiparâmetros de bancada HANNA C99, previamente calibrado.

Para reconhecer os corpos d'água e para delimitar valores máximos de cada parâmetro de qualidade e potabilidade foram utilizadas a Resolução CONAMA 357/05 e a Portaria 518/2004 do Ministério da Saúde. A avaliação da qualidade da água foi realizada através da metodologia do Índice Avaliação Integrada da Qualidade das águas - AIQA (IAP, 2005). Pode-se definir ainda a função $\mathbf{S}_{i}\left(\mathbf{D}_{i}\right) \operatorname{com} \mathbf{D}_{i}=\mathbf{f}_{i}^{\prime}-\mathbf{f}_{i}(\mathbf{x})$ que normaliza os desvios no intervalo $[\mathbf{0 , 1}]$, como:

$$
\begin{gathered}
S_{i}\left(D_{i}\right)=\underline{f_{i}^{\prime}-f_{i}(x)} \\
f^{\prime}{ }_{i}-f^{\prime \prime}{ }_{i}
\end{gathered}
$$

Sendo f" ${ }_{i}$ dado por

$\operatorname{Min}\left[f_{i}(x)\right]$ Sujeito a $\mathbf{x} €$ ?]

$i=1,2, \ldots, n$

Com esta transformação, uma solução de compromisso fica definida operacionalmente por:

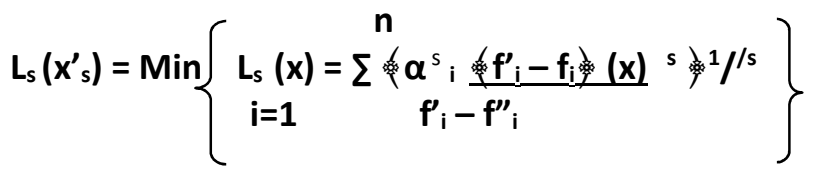

No entanto, quando se propõe a trabalhar com duas grandezas (qualidade físico-química e a qualidade microbiológica), aplica-se o princípio da normalização, delimitando um espaço cartesiano limitado pelas retas $\mathbf{Y}=\mathbf{0}, \mathbf{Y}=\mathbf{1}, \mathbf{X}=\mathbf{0}$ e $\mathbf{X = 1}$ (Figura 2 ). 


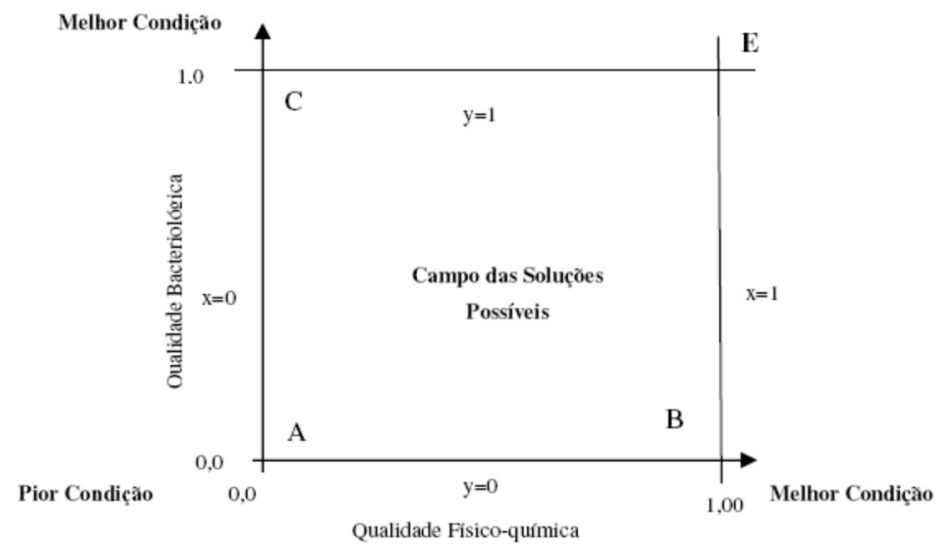

Figura 2: Campo das soluções possíveis do Indicador de Qualidade Integrada. Fonte: IAP (2009).

\section{RESULTADOS}

A bacia do Rio Pirarara possui $123,80 \mathrm{~km}^{2}$ que corresponde a $12.380,75$ hectares e apresenta ocupação diversificada, com destaque para área de ocupação urbana e na área rural com predomínio da agropecuária. As classes das terras encontradas nesta bacia podem ser observadas na Tabela 3.

Tabela 3: Quantificação das classes de uso das terras na bacia do rio Pirarara.

\begin{tabular}{|l|l|l|l|}
\hline Classes de uso da terra & Área $\mathbf{~ k m}^{\mathbf{2}}$ & (ha) & \% Relativa ao total \\
\hline Fragmento Florestal & 18,04 & $1.804,73$ & 14,57 \\
\hline Agrossilvipastoril & 97,53 & $9.753,02$ & 78,78 \\
\hline Área urbana & 7,78 & 778 & 6,29 \\
\hline Mineração & 0,45 & 45 & 0,36 \\
\hline
\end{tabular}

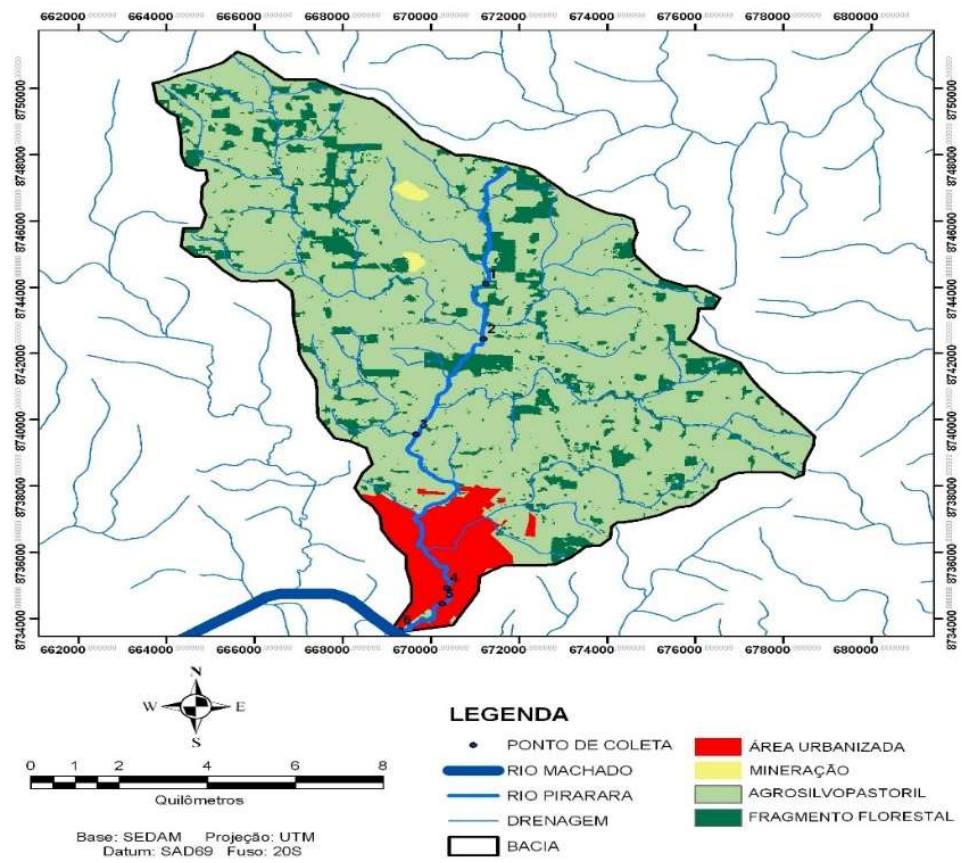

Figura 3: Mapa de uso e ocupação da bacia do Rio Pirarara. Fonte: INPE/SEDAM.

Na bacia em estudo a classe de maior porcentagem é a agrossilvipastoril, ocupando $78,78 \%$ da área total, ou seja, 9.753 hectares. As áreas com fragmentos florestais ocupam 14,57 \% da área, perfazendo 1.804,73 hectares. Já a área urbana abrange 6, 29 \% da área total da bacia. Já, as classes de uso e ocupação consideradas na bacia foram: mineração, fragmento florestal, agrossilvipastoril (áreas de lavoura 
permanente, temporária, pastagens e pecuária) e área urbana. O mapa de uso e ocupação, gerado pela classificação supervisionada da imagem LANDSAT, da bacia do Rio Pirarara encontra-se ilustrado na Figura 3.

Conforme o mapa de uso e ocupação o uso atual das terras é confirmado pela utilização das áreas com uso predominante agrossilvipastoril, com poucas áreas de vegetação natural. As áreas de reflorestamento e agricultura irrigada existentes, são pequenas em relação às áreas das demais classes de ocupação. As Classes do Rio Pirarara para cada parâmetro encontram-se no quadro 1. Entretanto, a Resolução Conama 357 não estabelece padrões para alguns parâmetros, permanecendo a referente linha no quadro 1 com a coloração em roxo, conforme indica a legenda.

Quadro 1: Classificação Resolução CONAMA no 357 de 17 de março de 2005.

\begin{tabular}{|l|l|l|l|l|l|l|}
\hline Variáveis & Ponto 01 & Ponto 02 & Ponto 03 & Ponto 04 & Ponto 05 & Ponto 06 \\
\hline Temperatura & 26,6 & 26,2 & 26,4 & 27,4 & 28,1 & 28,2 \\
\hline Cor & 75 & 74 & 76 & 79 & 76 & 77 \\
\hline Turdidez & 29,2 & 35,7 & 28,8 & 64,4 & 25,8 & 30 \\
\hline Ph & 6,6 & 6,8 & 6,1 & 6,5 & 6,8 & 6,7 \\
\hline Nitrato & 7,5 & 7,4 & 7,07 & 12,1 & 11,9 & 13,6 \\
\hline Nitrito & 3,5 & 1,9 & 1,8 & 3,3 & 0,3 & 2,2 \\
\hline OD & 7,5 & 4,9 & 4,6 & 6,5 & 3,7 & 2,8 \\
\hline DQO & 65 & 50 & 53,7 & 53,6 & 91,2 & 54,2 \\
\hline Fósforo & 1,8 & 2,6 & 1,8 & 1,7 & 0,8 & 1,4 \\
\hline Cromo & 0,18 & 0,20 & 0,21 & 0,13 & 0,28 & 0,37 \\
\hline Ferro & 1,68 & 2,01 & 2,06 & 2,18 & 1,95 & 2,00 \\
\hline Cobre & 0,52 & 0,65 & 0,59 & 0,85 & 0,59 & 0,60 \\
\hline Col. Fecais & 910 & 1700 & 1890 & 2355 & 2420 & 2695 \\
\hline Col. Totais & 1635 & 2655 & 3600 & 3785 & 4300 & 5930 \\
\hline
\end{tabular}

Classe $1 \square$ Classe $2 \square$ Classe $3 \square$ Não menciona $\square$ Fora das Classes

\section{DISCUSSÃO}

\section{Uso e ocupação das terras na bacia do Rio Pirarara}

O alto índice de desmatamento, principalmente nas décadas de 1970 e 1980 e o rápido processo de ocupação das áreas de influência do Rio Pirarara, associados à falta de fiscalização do poder público e ao cumprimento da legislação ambiental no município promoveu uma deterioração na qualidade hídrica do ambiente.

Ainda, de acordo com o mapa de uso e ocupação da Figura 3, as áreas de mineração, área urbana e fragmentos florestais apresentam menor percentagem de uso. No entanto, as áreas de vegetação compõemse de florestas naturais e reflorestadas. A mineração corresponde a 0,36\% da área da bacia, a atividade de mineração consiste na exploração de granito, brita e areia, conforme as fotos da figura 4. Estas formas de exploração podem ser caracterizadas como fonte pontual e não pontual de poluição que provocam poluição atmosférica e podem poluir o solo e os corpos d'água (LIBÂNIO, 2008).

As areias extraídas apresentam uma série de impactos ambientais, associados a sua retirada, onde se destaca o alargamento do leito fluvial e a retirada da mata ciliar que modificam o escoamento das águas, favorecendo a aceleração da erosão das margens, bem como o assoreamento do canal. Sabendo que as atividades humanas causam algum tipo de modificação na superfície da terra, a mineração talvez seja uma 
das que mais altera a forma do relevo. Neste sentido Guerra et al. (2010), ressaltam que as atividades de mineração podem causar a subsidência do relevo local, além de causarem danos ambientais e estéticos nos locais das escavações. As atividades de mineração podem ser apontadas como fontes potenciais de modificação das paisagens cársticas naturais, degradação do patrimônio morfológico e alteração da dinâmica hidrológica.

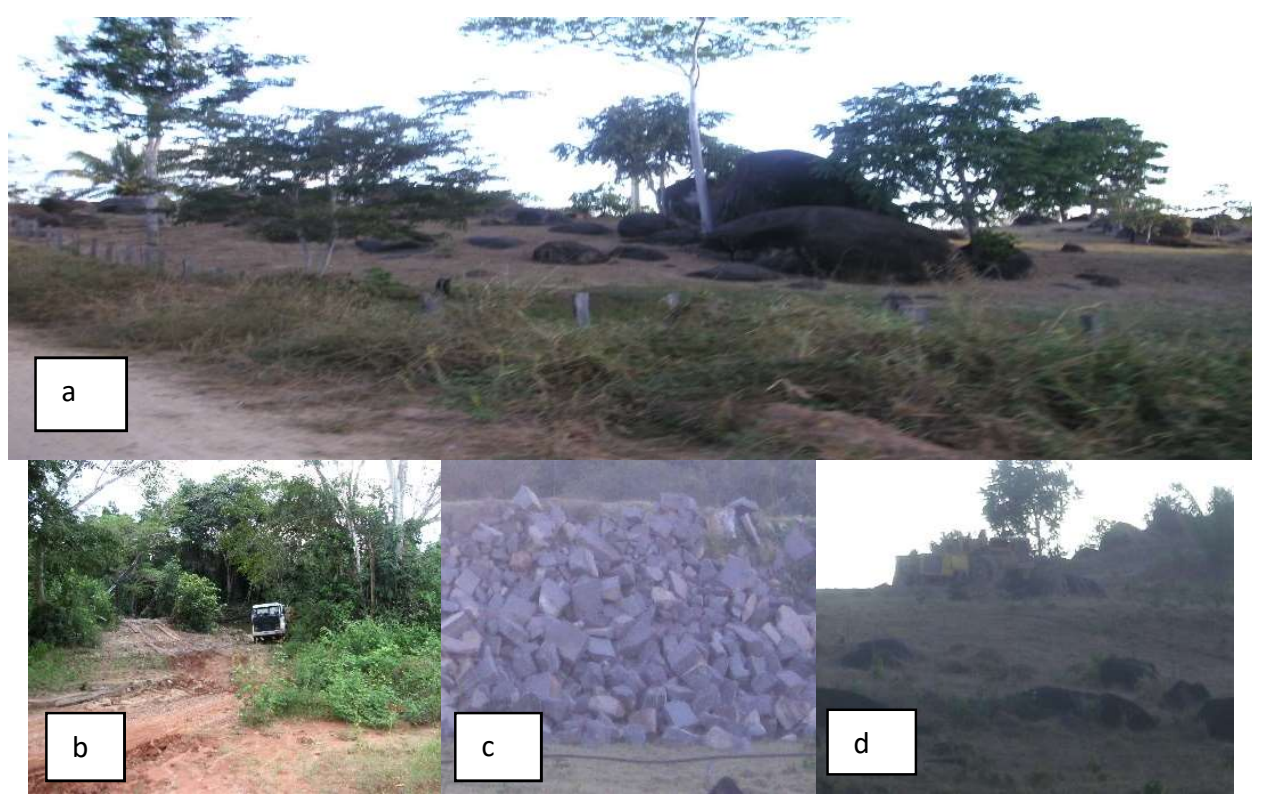

Figura 4: (a) Matacões às margens da linha sete- (b) área de mineração e exploração de areia no leito do Rio Pirarara; (c) pedaços de rocha granítica; e (d) máquinas utilizadas na explotação de granito. Fonte: Barbosa (2017).

Os rejeitos provenientes da exploração promovem impactos no local e em áreas, por vezes afastadas da área de mineração pelo escoamento superficial que transporta parte desse rejeito provocando assoreamento e poluição dos corpos d'água. Porém as características geomorfológicas são significativas, uma vez que muitos recursos minerais estão intimamente relacionados com as feições do relevo (GUERRA et al., 2010).

Os cultivos agrícolas trouxeram como consequência a exposição dos solos que contribuíram com os processos erosivos, facilitando o transporte de materiais para os cursos d'água levando ao assoreamento. Tais desmatamentos foram incentivados com os planos de desenvolvimento agrícola que foram traçados pelo Instituto Nacional de Colonização e Reforma Agrária (INCRA) sem que, fossem levadas em consideração as peculiaridades do solo. A retirada da vegetação pela prática do desmatamento foi incentivada como mecanismo para legitimar a posse da terra. Assim, a expansão da fronteira tinha como base a destruição da vegetação, pois ela representava o subdesenvolvimento da região. Lima et al. (2005) salientam que na década de 1970 o procedimento legal desta concepção era a concessão de títulos sobre seis hectares para cada hectare desmatado. Cabe salientar que essa política do desmatamento atualmente é inexistente e as discussões encontram-se direcionadas para a preservação ou ainda a recuperação das áreas que nas décadas passadas tiveram sua vegetação eliminada.

A região que abrange a bacia do rio Pirarara possui lavouras bem desenvolvidas, com boa produtividade, que estão ligadas às características físicas e a qualidade do solo, sendo considerado próprio para os vários tipos de cultura. Na agricultura permanente a base é a produção de café (sendo maior do 
estado, na década de 80), porém, de acordo com a EMATER, a produção vem decrescendo gradativamente seguida pela produção de banana; além de cultivos temporários, como o arroz, feijão, mandioca e o milho, sendo essas áreas substituídas pela pecuária, que vem se destacando ao longo dos anos na economia do Estado. No entanto, o IDARON salienta que o setor agropecuário em Cacoal encontra-se em plena expansão, e possui um dos maiores rebanhos do Estado, denominado como sexto maior em produção, com cerca de 463.671 cabeças (RONDÔNIA, 2017). Contudo, Carvalho (1996) destaca que a pecuária é apontada como um dos principais vetores de expansão da fronteira agrícola, ameaçando biomas como Cerrado e Amazônia, onde os baixos investimentos na manutenção de pastagem podem provocar compactação e erosão do solo.

O avanço da pecuária e as alterações promovidas pelo uso da terra têm sido considerado o principal agente de transformação na conversão de floresta por pastagens e têm proporcionado perdas de nutrientes do solo, transformando suas propriedades físicas e hídricas, principalmente em razão da compactação produzida pelo pisoteio animal, alterando o equilíbrio natural (SILVA FILHO, 2009).

O predomínio de pastagens na ocupação das terras na bacia dar-se-á principalmente para a criação de gado de corte e leite que, são comprovados através dos relatórios de dados da EMATER e do IDARON (RONDÔNIA, 2010), que corroboram com o avanço da pecuária sobre as áreas de cultivos agrícolas na bacia do Rio Pirarara.

O nitrogênio proveniente destes resíduos é convertido em amônia e nitrato que infiltra nas águas do subsolo e da superfície poluindo, contaminando e matando a vida aquática. Para Baird (2002), os excrementos produzidos pelos animais podem promover a contaminação dos cursos d'água, de forma difusa ou pontual. Carvalho (1996) afirma ainda, que a poluição dos recursos hídricos através da carga de nutrientes (nitrogênio, fósforo, potássio do esterco) e patógenos são carreados para o leito dos rios pela lixiviação do solo.

\section{Avaliação Integrada da Qualidade da Água}

Através dos resultados dos parâmetros físico-químicos e biológicos, foi realizada uma avaliação integrada da qualidade da água (AIQA) conforme tabela 4. Observando os valores numéricos do AIQA apresentados na Tabela 4 e no quadro 1, pode-se inferir que os valores obtidos na avaliação integrada da qualidade da água, indicam que a água encontra-se poluída. Alcançando classificação de medianamente poluída a extremamente poluída, onde o comprometimento da qualidade da água é atribuído a violação dos limites máximos da classe 2 do CONAMA para parâmetros físico-químicos e bacteriológicos. Apresentandose fora dos padrões estabelecidos no CONAMA 357/2005 para os rios de classe 2, obtendo equivalência na classe 3 no ponto 1 e nos demais pontos, classe 4 .

Tabela 4: Indicador da Qualidade da água (AIQA).

\begin{tabular}{|c|c|c|c|c|c|c|c|c|c|c|}
\hline Ponto & & Jan/2017 & & Fev/2017 & & Jun/2017 & & Jul/2017 & & Média AIQA \\
\hline 1 & 0,79 & Méd. Poluída & 0,79 & Méd. Poluída & 0,79 & Méd. Poluída & 0,79 & Méd. Poluída & 0,79 & Méd. Poluída \\
\hline 2 & 0,90 & Poluída & 0,90 & Poluída & 0,90 & Poluída & 0,90 & Poluída & 0,90 & Poluída \\
\hline 3 & 0,90 & Poluída & 0,90 & Poluída & 0,93 & Poluída & 0,93 & Poluída & 0,91 & Poluída \\
\hline 4 & 0,90 & Poluída & 0,90 & Poluída & 0,90 & Poluída & 0,93 & Poluída & 0,90 & Poluída \\
\hline 5 & 1,25 & Extr. Poluída & 1,06 & Muito Poluída & 1,06 & Muito Poluída & 0,90 & Poluída & 1,06 & MuitoPoluída \\
\hline 6 & 0,90 & Poluída & 0,90 & Poluída & 0,90 & Poluída & 0,90 & Poluída & 0,90 & Poluída \\
\hline
\end{tabular}


No ponto 1 os resultados indicam que a água está medianamente poluída, equivalente a classe 3 da classificação de qualidade estabelecida na Resolução CONAMA 357/05. Os parâmetros oxigênio dissolvido, $\mathrm{pH}$, fósforo, nitrito, nitrato, cobre, cromo e ferro, violaram o limites estabelecidos para classe 2 da Resolução Conama 357/2005.

No ponto 2 os resultados apresentados na Tabela 3 e no Gráfico 1 indicam que a qualidade da água é considerada poluída. Houve violação dos limites máximos da classe 2 do CONAMA para os parâmetros oxigênio dissolvido, fósforo, nitrito, coliformes, cobre, cromo e ferro. Essas violações são provavelmente ocasionadas pela entrada de resíduos de agrotóxicos usados em lavouras por se tratar de uma área agropastoril.

O ponto 3 tem a qualidade da água classificada como classe 4, considerada poluída. Os resultados apresentaram violação dos limites para os rios de classe 2, principalmente pela extrapolação dos limites de oxigênio dissolvido, fósforo, coliforme, ferro, cobre e cromo. Apesar, de não ocorrer despejos de efluentes industriais neste ponto, as violações se dão possivelmente em função de produtos químicos (fertilizantes) ricos em fósforo utilizados na agricultura, e durante o período chuvoso são carreados para o curso do rio, elevando as médias de forma significativa.

O ponto 4 tem sua situação de qualidade compatível com a classe 4 , considerada poluída. 0 comprometimento ocorre por violações da classe 2 da CONAMA, para fósforo, nitrito, nitrato, turbidez, ferro, cromo, cobre e coliformes. Essas violações são possivelmente decorrentes do lançamento de esgotos domésticos, lixiviação de criatórios de animais e pela utilização de defensivos a montante do ponto.

No ponto 5 a classificação da qualidade da água variou de poluída a extremamente poluída, apresentando-se como muito poluída na maior parte do período pesquisado. Cabe salientar que as condições pluviométricas no mês de janeiro ainda é reduzida e as condições de extremamente poluída para este período também pode ser relacionado com a redução do volume de precipitação nos meses de novembro e dezembro na região, período em que o curso d'água apresenta um redução em sua vazão. Os parâmetros oxigênio dissolvido, fósforo, nitrato, ferro, cromo, cobre e coliformes violaram os limites para rios de classe 2 da Resolução CONAMA 357/2005.

No ponto 6 a qualidade da água apresentou-se como classe 4, considerada poluída, devido à extrapolação dos limites de oxigênio dissolvido, fósforo, nitrito, nitrato, ferro, cromo, cobre e coliforme, devido ao lançamento de esgotos domésticos e outros materiais de origem orgânica. A avaliação integrada da qualidade da água (AIQA) do rio Pirarara identificou poluição em todos os ponto de amostragem, os valores referentes as médias dos pontos analisados no rio Pirarara podem ser vizualizados no gráfico 1.

A influência de um processo de ocupação de forma desordenada é considerada um fator que contribuiu para a ocorrência da deterioração da qualidade da água, pois as normas de uso e ocupação de bacias hidrográficas respeitando a legislação não são observadas. No entanto, podendo inferir que, as regras designadas pelo Plano Diretor do município, em sua maioria não são respeitadas. Entretanto, Tucci (2002) destaca que, dentre as consequências ambientais e sociais produzidas pela ocupação urbana se destaca a introdução de superfícies impermeáveis que reduz a infiltração e diminui a superfície de retenção, 
aumentando o escoamento superficial provocando as enchentes em áreas urbanas. Assim, a combinação dos fatores do meio físico (chuvas, solo, cobertura vegetal, rede de drenagem, etc.) e os impactos provocados pela ocupação humana, induzem e/ou causam aceleração dos processos geomorfológicos (GUERRA et al., 2010).

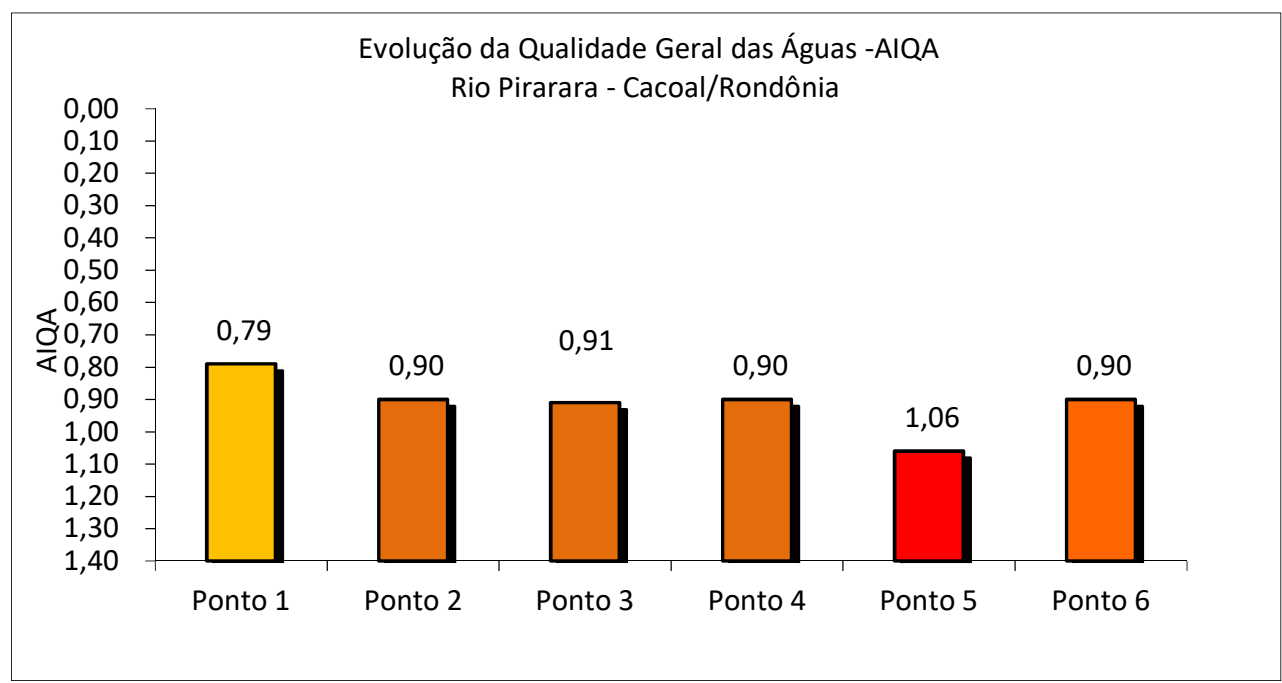

\begin{tabular}{|ccccccc|}
\hline Muito boa & Boa & $\begin{array}{c}\text { Pouco } \\
\text { poluída }\end{array}$ & $\begin{array}{c}\text { Medianame } \\
\text { nte poluída }\end{array}$ & Poluída & $\begin{array}{c}\text { Muito } \\
\text { Poluída }\end{array}$ & $\begin{array}{c}\text { Extrema } \\
\text { mente } \\
\text { poluída }\end{array}$ \\
0,0 a 0,2 & $>0,2$ a 0,4 & $>0,4$ a 0,6 & $>0,6$ a 0,8 & $>0,8$ a 1,00 & $>1,00$ a 1,20 & $>1,20$ \\
\hline \multicolumn{8}{c|}{ Qualidade Geral - AIQA } \\
\hline
\end{tabular}

Gráfico 1: Evolução da Qualidade da água do Rio Pirarara nos pontos pesquisados.

O cerceamento da qualidade hídrica ocorre principalmente através do despejo de esgoto, devido à presença de contaminantes típicos de esgotos domésticos e a detecção de esgotos de indústrias e serviços. A implantação de obras de coleta eficiente, tratamento de esgoto e a regulamentação do uso e ocupação do solo, são fatores que contribuem com a melhoria da qualidade da água.

Assim, através do cálculo do AIQA, objetivou-se fazer uma avaliação integrada (físico-química e biológica), das consequências da poluição sobre a qualidade da água, entretanto, acredita-se que este instrumento possa atenuar as dúvidas referentes a influência do uso e ocupação na qualidade hídrica da bacia. Desta forma verifica-se que na bacia do Rio Pirarara há um predomínio da ação antrópica. Corroborando, que os processos de uso da terra possuem forte influência na qualidade da água e que a utilização de bacias hidrográficas em áreas onde há interferências antrópicas, precisa ser planejada, com a finalidade de um adequado ordenamento territorial.

\section{CONCLUSÕES}

A evolução da ocupação, promovida pela intensa urbanização, principalmente a partir das décadas de 1980 e 1990 e os loteamentos implantados na área de influência do baixo curso do Rio Pirarara promoveu o aumento da impermeabilização do solo. Outro efeito observado da relação entre o uso do solo nas atividades agrossilvipastoril (agricultura, pecuária) que compõem a paisagem rural predominante na área da bacia. 
Os dados apresentados nesta pesquisa e seus respectivos instrumentos visam a melhoria dos processos de gestão e, consequentemente, o uso e ocupação das terras na bacia do Rio Pirarara. Este estudo confirmou as alterações provocadas em virtude da influência das mudanças no uso da terra na área da bacia, evidenciando que o gerenciamento dos componentes terrestres e aquáticos devem ser tratados conjuntamente. Pois a qualidade hídrica apresentou-se alterada na avaliação integrada, confirmando a influência de uso e ocupação na qualidade da água da bacia. No entanto, há uma necessidade de levantamentos mais detalhados para que se conheçam as propriedades e capacidades para o desenvolvimento de algumas atividades específicas de uso da terra, desta forma evitaria a utilização de áreas impróprias. A identificação das classes de solo dominante na região torna-se um instrumento imprescindível na avaliação integrada e planejamento de uso da terra.

\section{REFERÊNCIAS}

APHA; AWWA; WPCF. Standard methods for the examination of water and wastewater. 21 edition. Wasghington: American Public Health Association, 2005.

BAIRD, C.. Química Ambiental. 2 ed. Porto Alegre: Bookman, 2002.

BOTELHO, R. G. M.; ROSSATO, M. S.. Erosão em áreas urbanas no Brasil: formas de ocorrência e fatores agravantes. In: ENCONTRO NACIONAL DE GEÓGRAFOS, 13. Anais. João Pessoa, 2002.

BRASIL. Portaria MS n.518/2004: Estabelece os procedimentos e responsabilidades relativos ao controle e vigilância da qualidade da água para consumo humano e seu padrão de potabilidade, e dá outras providências, Brasília: DOU, 2004

BRASIL. Resolução CONAMA n.357/2005: Dispõe sobre a classificação dos corpos d'água e direitos ambientais para o seu enquadramento, bem como estabelece as condições e padrões de lançamentos de efluentes e da outras providências. Complementada pela Resolução no 393, de 2009. CONAMA. Conselho Nacional de Meio Ambiente, Brasília: DOU, 2005.

BUENO, L. F.; GALBIATTI, J. A.; BORGES, M. J..

Monitoramento de variáveis de qualidade de água no horto Ouro Verde/Conchal/SP. Ver. Engenharia Agrícola, Jaboticabal, v.25, n.3, p.742-748, 2005. DOI: http://dx.doi.org/10.1590/S0100-69162005000300020

CARVALHO, A. R.. Relações da atividade agropecuária com parâmetros físico-químicos da água. Dissertação (Mestrado em Ciências da Engenharia Ambiental) - Universidade de São Paulo, São Carlos, 1996.

CAVALHEIRO, F.. Urbanização e alterações ambientais. In: TORNISIELO, S. M. T.; GOBBI, N.; FOWLER, H. G.. Análise Ambiental: uma visão multidisciplinar. 2 ed. UNESP, 1995.

COSTA, A. J. S. T.. Hidrogeografia e a cidade do Rio de Janeiro. In: MARAFON, G. J.; RIBEIRO, M. F.. Estudos de Geografia Fluminense. Rio de Janeiro: Infobook Ltda, 2002.
GUERRA, A. J. T.; CUNHA, S. B.. Degradação Ambiental. In. Geomorfologia e Meio Ambiente. GUERRA, A. J. T; CUNHA, S. B.. Rio de Janeiro: Bertrand Brasil, 1996, p.337-380.

GUERRA, A. J. T.; MARÇAL, M. S.. Geomorfologia Ambiental. 3 ed. Rio de Janeiro: Bertrand Brasil, 2010.

INPE. Instituto Nacional de Pesquisas Espaciais. Monitoramento da floresta Amazônica brasileira por satélite (Projeto PRODES). São José dos Campos, 2017.

IAP. Instituto Ambiental do Paraná. Relatório de Monitoramento da Qualidade das águas dos rios da região de Curitiba, no período de 1992 a 2005. Curitiba, 2005.

IAP. Instituto Ambiental do Paraná. Método da Avaliação Integrada da Qualidade das Águas/AIQA. Curitiba, 2009.

LIBÂNIO, M.. Fundamentos de qualidade e tratamento de água. 2 ed. Campinas: Átomo, 2008.

LIMA, D.; POZZOBON, J.. Amazônia socioambiental: sustentabilidade ecológica e diversidade social. Estudos Avançados. São Paulo, v.19, n.54, p.45-76, 2005.

MENDONÇA, F. S. A. U.. Sistema Ambiental Urbano: Uma abordagem dos problemas socioambientais da cidade. In: MENDONÇA, F.. Impactos socioambientais urbanos. Curitiba: UFPR, 2004.

MORAES, A. C. R.. A valorização do Espaço. 4 ed. São Paulo: Hucitec, 1984

PEREIRA, V. P.. Solo: Manejo e Controle de erosão hídrica. Jaboticabal: FCAV, 1997.

PORTO, R.; ZAHED FILHO, K.; TUCCI, C.; BIDONE, F.. Drenagem urbana. In: TUCCI, C. E. M.. Hidrologia: Ciência e aplicação. 2 ed. Porto Alegre: UFRGS/ABRH, 2001.

RONDÔNIA. Governo do Estado de Rondônia. Secretaria de Estado de Planejamento e Coordenação Geral (SEPLAN/RO). Zoneamento Sócio-Econômico e Ecológico do Estado de Rondônia (ZSEE-RO). Planejamento para o desenvolvimento sustentável e proteção ambiental. Porto Velho, 2010. 
RONDÔNIA. Governo do Estado de Rondônia. Relatório da Agência de Defesa Sanitária Agrossilvipastoril do Estado de Rondônia. IDARON, 2017.

SEDAM. Atlas Geoambiental de Rondônia, Porto Velho: SEDAM, 2002.

SILVA FILHO, E. P.. Estudo da Degradação dos Solos em Áreas de Pastagens no Município de Porto Velho/RO. Tese (Doutorado em Geociências e Meio Ambiente) Universidade Estadual Paulista, Rio Claro, 2009.
SILVA, M. J. G.. Boletim Climatológico de Rondônia de 2006. Porto Velho: SEDAM, 2006.

TUCCI, C. E. M.. Hidrologia: ciência e aplicação. 3 ed. Porto Alegre: UFRGS/ABRH, 2002.

VITTE, A. C.; GUERRA, A. J. T.. Reflexões sobre a Geografia Física no Brasil. Rio de Janeiro: Bertrand Brasil, 2004.

A CBPC - Companhia Brasileira de Produção Científica (CNPJ: 11.221.422/0001-03) detém os direitos materiais desta publicação. Os direitos referem-se à publicação do trabalho em qualquer parte do mundo, incluindo os direitos às renovações, expansões e disseminações da contribuição, bem como outros direitos subsidiários. Todos os trabalhos publicados eletronicamente poderão posteriormente ser publicados em coletâneas impressas sob coordenação da Sustenere Publishing, da Companhia Brasileira de Produção Científica e seus parceiros autorizados. Os (as) autores (as) preservam os direitos autorais, mas não têm permissão para a publicação da contribuição em outro meio, impresso ou digital, em português ou em tradução. 